\title{
Limited evidence for interceptive extraction of deciduous canines to prevent permanent canine impaction
}

\section{Abstracted from}

\section{Naoumova J, Kurol J, Kjellberg $\mathbf{H}$.}

A systematic review of the interceptive treatment of palatally displaced maxillary canines. Eur J Orthod. 2011; 33: 143-149. Epub 2010 Jul 14. Review. PubMed PMID: 20631081.

Address for correspondence: Dr. Julia Naoumova, Department of Orthodontics, Institute of Odontology at the Sahlgrenska Academy, University of Gothenburg, Göteborg, Sweden. E-mail: julia.naoumova@vgregion.se

\section{Question: Does interceptive treatment in the mixed dentition prevent the impaction of the palatally displaced maxillary permanent canine (PDC)?}

Data sources PubMed, the Cochrane Library electronic databases and Scopus were searched.

Study selection Randomised controlled trials (RCT), prospective and retrospective studies with untreated controls and clinical trials comparing at least two treatment strategies conducted in the mixed dentition with unilateral or bilateral PDC were included.

Data extraction and synthesis Three reviewers selected and extracted the data independently and evaluated the quality of the studies. Interexaminer reliability was measured using the intraclass correlation coefficient (ICC).

Results Owing to heterogeneity in the study methods and unequivocal results, the scientific evidence was too weak to evaluate the effect of interceptive treatment on PDC or which treatment modalities are most effective. The quality of the studies is low due to inadequate sample selection and deficient description of sample size, confounding factors, uncertainty of randomisation and no blinding in measurements.

Conclusions To obtain reliable scientific evidence as to whether interceptive treatment prevents impaction of PDC and which treatment modalities are the most effective, better controlled and well-designed RCTs are needed. Future studies should also include assessment of patient satisfaction and pain experience as well as analysis of the costs and side-effects of treatments.

\section{Commentary}

'The best birthday present you can give to a ten-year-old is to palpate their upper canines.' This was advice I received during my orthodontic training. Although only a small number $(1-3 \%)$ of maxillary canines do not erupt correctly, ${ }^{1,2}$ the sequelae are numerous, including root resorption of neighbouring teeth, cyst formation, movement of adjacent teeth and dental crowding. ${ }^{3}$ The majority (85\%) move palatally while the remaining $15 \%$ impact in the buccal sulcus. ${ }^{4}$ Unless a decision is made to leave and monitor the tooth, treatment commonly involves surgical exposure and prolonged orthodontic treatment with fixed appliances. Thus, any interceptive treatment that will reliably increase the chance of eruption into or close to the line of the arch must be considered. One commonly practised intervention is the early extraction of the deciduous canine in individuals where clinical and radiographic examination shows the permanent canine developing ectopically. This study by Naoumova et al. aims to assess the effectiveness of the interceptive extraction of deciduous canines.

Amongst the 686 studies yielded in the search strategy was the paper by Ericsson and Kurol, ${ }^{5}$ often cited by practitioners as evidence for the effectiveness of this treatment. The study was excluded in this review, as, although prospective in design, it was a cohort study without a control group. It is salutary to consider that 23 years on, only two studies ${ }^{6,7}$ fulfilled the criteria for inclusion in this current systematic review, and for both studies, the research quality and methodological standards were assessed to have a low value (grade C) of evidence.

Although both were prospective controlled clinical trials, neither defined what they meant by a palatally displaced canine. The study by Leonardi ${ }^{6}$ had further limitations. These included a lack of clarity regarding the method of randomisation and blinding of the researchers, differences between the treatment and control groups, no sample size calculations and lack of descriptive statistics. Although the study by Baccetti ${ }^{7}$ had a satisfactory sample size and included a power analysis, there were some queries about blinding to group allocation as well as details regarding the position of the displaced canine at the start of treatment.

This systematic review has been carried out well, although interestingly, it is very similar to the Cochrane review carried out by Parkin et al. ${ }^{8}$ and comes to similar conclusions.

For practitioners, therefore, the question remains 'Is it prudent to extract a deciduous maxillary canine in a 10- to 13 -year-old child where the permanent successor is clearly developing ectopically?' A general practitioner faced with this clinical situation 
has to make a decision whether to leave and observe, extract the deciduous canine or request exposure of the permanent successor. This decision will be made in the light of a lack of strong evidence. In many of these cases there will be other features of a malocclusion requiring orthodontic treatment. I would therefore strongly recommend referring such a patient to a specialist orthodontist.

\section{Practice points}

- Include palpation of the maxillary canines in your clinical examination of all patients aged nine and over if the upper permanent canines have not erupted.

- If you have doubts about the position of an unerupted maxillary canine, refer promptly for a specialist orthodontic opinion.
Julian O'Neill

Orthodontic Department, Kettering General Hospital NHS

Foundation Trust, Kettering, UK

1. Kramer RM, Williams AC. The incidence of impacted teeth. A survey at Harlem Hospital. Oral Surg Oral Med Oral Path 1970; 29: 237-241.

2. Grover PS, Lorton L. The incidence of unerupted permanent teeth and related clinical cases. Oral Surg Oral Med Oral Pathol 1985; 59: 420-425.

3. Shafer WG, Hine MK, Levy BM. A textbook of oral pathology. 2nd ed. Philadelphia: WB Saunders, 1963.

4. Ericson $S$, Kurol I. Radiographic examination of ectopically erupting maxillary canines. Am J Orthod Dentofacial Orthop 1987; 91: 483-492.

5. Ericson $\mathrm{S}$, Kurol J. Early treatment of palatally erupting maxillary canines by extraction of the primary canines. Eur J Orthod 1988; 10: 283-295.

6. Leonardi M, Armi P, Franchi L, Baccetti T. Two interceptive approaches to palatally displaced canines: a prospective longitudinal study. Angle Orthod 2004; 74: 581-586.

7. Baccetti T, Leonardi M, Armi P. A randomized clinical study of two interceptive approaches to palatally displaced canines. Eur J Orthod 2008; 30: 381- 385.

8. Parkin N, Benson PE, Shah A. Extraction of primary (baby) teeth for unerupted palatally displaced permanent canine teeth in children. Cochrane Database Syst Rev. 2009, Issue 2.

Evidence-Based Dentistry (2011) 12, 106-107. doi:10.1038/sj.ebd.6400824 